\title{
Overview of Tips in Overcoming Learning Curve in Uniportal and Biportal Endoscopic Spine Surgery
}

\author{
Pang Hung $\mathrm{Wu}^{1}$, Hyeun Sung $\mathrm{Kim}^{2}$, Dae Jung $\mathrm{Choi}^{3}$, Yu-Heng Tan Gamaliel ${ }^{1}$ \\ ${ }^{1}$ Departments of Orthopaedic Surgery, National University Health System, Jurong Health Campus, Singapore \\ ${ }^{2}$ Departments of Neurosurgery, Nanoori Gangnam Hospital, Spine Surgery, Seoul, Republic of Korea \\ ${ }^{3}$ Departments of Orthopaedic Surgery, Himnaera Hospital, Spine Surgery, Busan, Republic of Korea
}

Corresponding Author:

Pang Hung Wu, MBBS, FRCS

Departments of Orthopaedic Surgery, National University Health System,

Jurong Health Campus, 1 Jurong East Street 21, Singapore 609606, Singapore Email: wupanghung@gmail.com

Received: January 7, 2021 Revised: February 12, 2021

Accepted: February 15, 2021

\begin{abstract}
There is increasing trend of spine surgeries performed with uniportal and biportal endoscopic spine surgery. Despite its good outcomes and supportive literature, the proportion of spine surgeons regularly doing endoscopic spine surgeries is relatively low. The main limitation is the steep learning curve in the early phase of endoscopic spine surgeries practice. There is paucity of literature in discussion of tips in overcoming these 2 schools of endoscopic spine surgery practice. In this tips and tricks overview, the authors highlights the key differences these 2 main school of endoscopic spine surgeries practice with specific discussions pertaining to "BIPORTALS": the areas of basic medium of surgery, instruments for visualization and working, placement of portal(s), outflow of fluids, route of approach, technical challenges, anatomical challenges, location of lens and light source and start point to work. A ladder of progression of endoscopic spine surgery is proposed to effectively ease into the practice of endoscopic spine surgery.
\end{abstract}

Key Words: Endoscopic spine surgery, Spinal fellowship, Endoscopy, Patients' outcome, Training program in surgery

\section{INTRODUCTION}

There is a growing trend and demand for minimally invasive spine surgery and in particular endoscopic spine surgery ${ }^{29)}$. The common goal of achieving maximal amount of benefit with the least amount of soft tissue damages is the main aim of endoscopic spine surgery ${ }^{30,54)}$. The advantages of endoscopic spine surgery is provided by water irrigation surgery, improvements in visualization with magnification of spinal structures, safe delivery of energy and spinal instruments to target tissues to minimize collateral damages to tissues ${ }^{13)}$.

However there is a steep learning curve for spine surgeons in endoscopic spine surgery $y^{6}$. This is confounded by complexity of spinal procedures and generally higher risk procedures in spine surgery. There is a lack of training in handling of equipment which are specifically designed for endoscopic spine surgery during residency coupled with the paucity of endoscopic spine surgeon in the population of spine surgeon are some of the issues which limits the spread of practice in endoscopic spine surger ${ }^{52}$. In this editorial, we highlight the challenges in the early phase of endoscopic spine surgery and the steps to mitigate complications and improve outcomes during this difficult learn- ing curve period. We use the mnemonics BIPORTALS, namely basic medium, instruments/visualization, placement of portals, outflow of fluids, route of approach, technical/anatomical challenges, location of lens and light source and start point to work to highlight the differences among the 3 common types of minimally invasive and endoscopic surgeries and discuss strategies to overcome the differences and challenges in the different types of surgeries. A ladder of progression of endoscopic spine surgery is proposed to progressively ease into the practice of endoscopic spine surgery.

\section{Basic Medium}

Tubular microscopic surgery utilizes air base medium by exposure of a tract to the sterile surgical environment from skin to the target anatomy filled with $\mathrm{air}^{3}$. . This is a familiar environment for most surgeons as we are used to open procedures during surgical training. The main disadvantage is the requirement of frequent suction and the use of bipolar and monopolar diathermy for hemostasis and visualization ${ }^{177}$. It is debatable that exposure of wound to airflow in operating room environment might increase risk of infection. The use of laminar airflow has shown to decrease the risk of infection ${ }^{40)}$. 
Uniportal and biportal endoscopic surgeries are performed under water based medium. Constant irrigation with saline with/ without antibiotic solution has the advantages of provision of clarity of visualization by decreasing bleeding from capillaries, constant elimination of bone dust and loose soft tissue by the outflow current and potential decrease in infection risk ${ }^{48,50)}$. The use of water medium however brings the risk of water pressure related complications to central nervous systems. Water based complications such as soft tissue edema, cerebral edema, post-operative neck pain ${ }^{22)}$. Recently, Kang et al showed that an irrigation pressure of mean $30 \mathrm{mmHg}$ is safe for irrigation based surgeries ${ }^{19)}$. It is a good practice to lower the pressure at the completion of the procedures to allow good hemostasis with radiofrequency ablation.

\section{Instruments and Visualization}

\section{1) Retractor Tube, Endoscope and Working Instruments}

In tubular surgery, soft tissue adjacent to bony target is retracted by accurate placement of tubular retractor under fluoroscopic guidance. It is imperative for the accurate placement of tube to minimize soft tissue damages and decrease operative time. Preoperative plans are made for accurate placement of the tubular retractor ${ }^{36}$. Microscope is used for visualization. These equipment are generally available in most hospitals with spine and neurosurgical practice. Spine surgeons are generally familiar in handling the microscope, though dedicated training might be required to be competent in tubular surgery ${ }^{42)}$.

Uniportal ESS on the other hand requires specific endoscope and dedicated instruments in each type of endoscopic approaches. In transforaminal endoscopic lumbar discectomy (TELD), a higher degree ocular angle endoscope(25-35 degree) than interlaminar endoscope (10-20 degrees) is required to visualize tissue in a limited working space with endoscope often docked at an angle to the target disc ${ }^{47,58)}$. The endoscope is longer than interlaminar endoscope as the skin incision made tends to be further from target disc. A longer transforaminal endoscope might be required in patients with high body mass index ${ }^{20)}$.

The instruments in transforaminal approach are correspondingly longer than those used in interlaminar discectomy endoscope. Wider working channel dimensions endoscope and its correspondingly larger dimension endoscopic instruments are provided for lumbar endoscopic unilateral laminotomy with bilateral decompression (LEULBD) designed to use for stenosis cases ${ }^{23,37)}$. Biportal ESS on the other hand uses mostly open spine general equipment and orthopaedic arthroscope. As the surgeon tends to stand in the same position throughout the procedure, typically using his dominant hand to handle power tools and sharp instruments, there are modified equipment such as rotatory Kerisson rongeurs, semi/full tubular working portal retractor, angled osteotomes which facilitate BESS/UBE working through a small working portal ${ }^{18)}$. Unlike knee and shoulder arthroscopy which tends to use angled degree scope, 0 degree scope is popular in BESS/UBE. More than 1 working instruments for example retractor and Kerrison rongeur can be used simultaneously in tubu- lar and BESS/UBE while in uniportal ESS, there is space only for one instrument to pass through working channel at one time. Typically working beveled tip cannula can be used a substitute for neural or soft tissue retraction in uniportal endos- copic spine surgery.

As working instruments are inserted into patient's body from a separate portal, it is important to pull back endoscope to visualize the entry of the working instruments for beginners. Non visualized insertion of instruments can lead to instruments causing damages and injuries.

\section{Endoscopic Drill and Energy System}

In microscopic surgery, an air based angled handle drill of standard length can be placed through the tube. Bone dust is washed away by assistant providing irrigation and suction. The choice of drill bits is according to surgeon's preference. Side cutting burr is a popular choice in tubular surgery as it is efficient and the blunt tip decrease chances of injury to the neural elements.

In both Uniportal and Biportal ESS, the endoscopic drill needs to be water resistant, compatible in water based surgical environment ${ }^{54,56)}$. Biportal ESS uses standard working length drill is similar to microscopic surgery, a straight handle is recommended and the surgeon holds the drill on right hand only most of the time during surgery. In Uniportal ESS, the length and dimension of the drill varies according to the dimension of the working channel of each type of endoscope. The drill has a relatively longer handle and hence the rotating burr is of a long distance away from the motor, careful manipulation of the drill is important to prevent injuries to neural elements. Diamond burr is popular for both uniportal and biportal ESS as it generates heat and helps in hemostasis during drilling. Bone dust is constantly washed away by endoscopic irrigation.

The technique in handling uniportal and biportal ESS is very different. In Uniportal ESS, drilling is done collinear to the scope view, surgeon has to manipulate by rotating the endoscope to have better visualization of the tip of the drill and tissue it is working on. The drill is held with dominant hand with the nondominant hand holding the endoscope and supporting the drill with a finger (Figure 1A). In Biportal ESS, the drill is held by dominant hand only without the support of non-dominant hand from a separate working portal (Figure 1B). The viewing scope visualize the tip of the drill at an angle of 30-90 degrees.

Figure 1A: Handling of Uniportal endoscope with non-dominant hand maneuverers the endoscope and dominant hand $(\mathrm{DH})$ holding the working instruments place through the working channel. Figure 1B: Non-dominant hand(NDH) holding the endoscope from viewing portal and dominant hand holding working instruments placed through a separate working portal.

Due to limited working space available, care must be taken to prevent drilling of the lens which would damage the endoscope. The trick is to past point the drill during drilling, keeping the drill at 10-11 o'clock position during initial drilling at a limited working space in Biportal ESS (Figure 2A). While in Uniportal ESS, endoscopic drill that should be completely stopped and at rest before retraction back into the working channel of the 


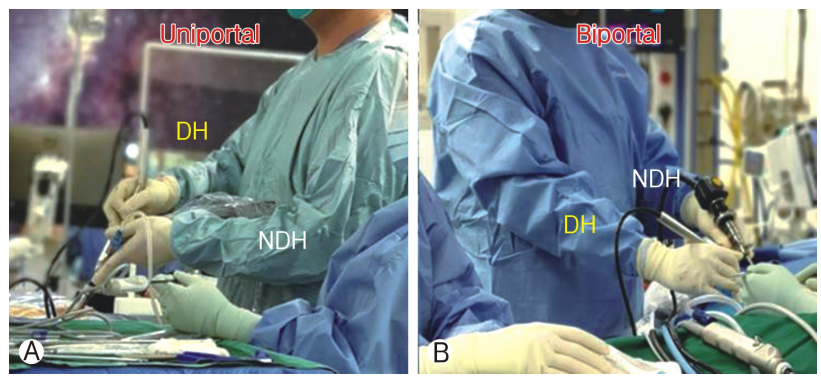

Figure 1. (A): Handling of Uniportal endoscope with non-dominant hand maneuverers the endoscope and dominant hand $(\mathrm{DH})$ holding the working instruments place through the working channel. (B): Nondominant hand (NDH) holding the endoscope from viewing portal and dominant hand holding working instruments placed through a sepa- rate working portal.

endoscope (Figure 2B). During uniportal endoscopic drilling , surgeon needs to keep the drill collinear with the endoscope which in turns is collinear with working retractor tube, any bending forces on the drill cause drill breakage due to long lever arm of the endoscopic drill, while any bending forces on the endoscope cause breakage of the endoscopic lens.

Electrical energy in central nervous system in general and spine in particular are of a different energy setting as compared to limb orthopaedic surgery. Surgeons who are doing each of these techniques have to familiarize themselves with the limitations of the technique and derive a workflow to overcome these challenges. In both uniportal and biportal ESS, low energy radiofrequency ablator is compatible with work near dura region is generally used for hemostasis (Figure 2C). High energy radiofrequency ablator is optional in uniportal ESS, often used in stenosis decompression due to higher workload of bony decompression and corresponding soft tissue dissection. High energy radiofrequency ablator is however strongly recommended as a requirement for biportal ESS as there is much work in soft tissue dissection and for triangulation and creation of working space in the sublaminar region deep to spinal muscles but dorsal to the deep ligamentum flavum (Figure 2D). In this specific zone of interlaminar region and sublaminar space, the energy setting range is very specific, higher than the energy required in radiofrequency ablation for spine pain procedures but lower than limb orthopaedic surgery setting. If energy is too high it can cause a phenomenon which is similar to Electric Convulsive Therapy (ECT) which can cause patient to be in a stupor state or worst scenario of cardiac complications such as asystole $e^{45}$. We do not recommend use of arthroscopic setting use in knee and shoulder to be use in spine ${ }^{511}$. While an energy setting which is too close to low energy radiofrequency ablation may not be efficient in soft tissue dissection in a layer dorsal to ligamentum flavum. It is important to check whether the energy machine used is specific for spinal water based surgery with both compatible high and low energy radiofrequency ablation is available $e^{4)}$.

Figure 2A: Endoscopic drill is visualized at 10-11 o'clock position of the endoscope past pointing the endoscope during initial drilling in a limited working space in Biportal Endoscopic Spine
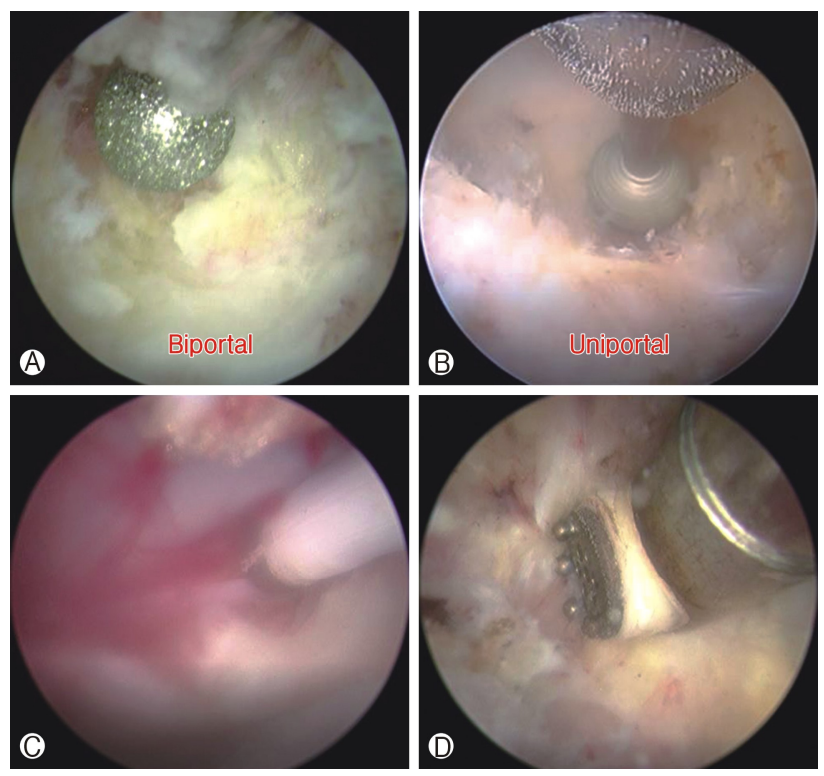

Figure 2. (A): Endoscopic drill is visualized at 10-11 o'clock position of the endoscope past pointing the endoscope during initial drilling in a limited working space in biportal endoscopic spine surgery to prevent damages of endoscope to prevent lens damages. (B): In uniportal endoscopic spine surgery endoscopic drill is in forward position relative to endoscope. Endoscopic drill that should be completely stopped before retraction back into the working channel of the endoscope to prevent lens damages. (C): Low energy radiofrequency ablation is compatible with work near dura region for hemostasis which is applicable for both uniportal and biportal endoscopic spine surgeries. (D): Higher energy radiofrequency ablation can be applied to soft tissue dorsal to deep layer of ligamentum flavum to allow more efficient soft tissue dissection, different length and dimensions are applicable for high radiofrequency ablation applicators in uniportal and biportal endoscopic spine surgeries.

Surgery to prevent damages of endoscope to prevent lens damages. Figure 2B: In uniportal endoscopic spine surgery endoscopic drill is in forward position relative to endoscope. Endoscopic drill that should be completely stopped before retraction back into the working channel of the endoscope to prevent lens damages. Figure 2C: Low energy radiofrequency ablation is compatible with work near dura region for hemostasis which is applicable for both uniportal and biportal endoscopic spine surgeries. Figure 2D: Higher energy radiofrequency ablation can be applied to soft tissue dorsal to deep layer of ligamentum flavum to allow more efficient soft tissue dissection, different length and dimensions are applicable for high radiofrequency ablation applicators in uniportal and biportal endoscopic spine surgeries.

Choice of Biportal and Uniportal ESS. Both biportal and uniportal ESS techniques have their merits and disadvantages (Table 1). It is imperative for the surgeon to understand his local community facilities and equipment support to see the feasibility of his ESS practice.

In Uniportal ESS, the equipment required is generally specifically designed for use in Uniportal ESS as there are various diffe- 
Tips and Tricks in Uniportal and Biportal Endoscopic Spine Surgery

Table 1. Differences in tubular microscopic spine surgery, Uniportal endoscopic spine surgery and biportal endoscopic spine surgery

\begin{tabular}{|c|c|c|c|}
\hline $\begin{array}{l}\text { Types of MIS } \\
\text { Surgery }\end{array}$ & Tubular Microscopic & Uniportal Endoscopic Spine Surgery & Biportal Endoscopic Spine Surgery \\
\hline Basic Medium & Air & Water & Water \\
\hline \multirow[t]{7}{*}{$\begin{array}{l}\text { Instruments For } \\
\text { Visualization and } \\
\text { Working }\end{array}$} & Tubes, tube holder, microscope & $\begin{array}{l}\text { Various different types of Endoscope } \\
\text { (differences in angle of scope, length, size of } \\
\text { working channel with each scope having a } \\
\text { separate set of specialized instruments. } \\
\text { optic/camera angle varied depending on type } \\
\text { of scope (transforaminal higher angle around } \\
25-30 \text { deg), interlaminar around } 10-20 \mathrm{deg}\end{array}$ & $\begin{array}{l}\text { Biportal Endoscopic Spine Surgery } \\
\text { System } \\
\text { Optic zero-30 degree/camera }\end{array}$ \\
\hline & $\begin{array}{l}\text { Few Specialized equipment/Spe- } \\
\text { cialized tray (angulated forceps/ } \\
\text { kerrison), mainly general equip- } \\
\text { ment which can be used in open } \\
\text { surgery }\end{array}$ & $\begin{array}{l}\text { All are specialized instruments designed to be } \\
\text { used with the type of endoscope. Uniportal } \\
\text { instruments are not useful in open surgery }\end{array}$ & $\begin{array}{l}\text { Few specialized equipment, mainly } \\
\text { general equipment which can be } \\
\text { used in open surgery }\end{array}$ \\
\hline & Numbers of instruments $(\geq 1)$ & Numbers of instruments $(=1)$ & Numbers of instruments $(\geq 1)$ \\
\hline & $\begin{array}{l}\text { Working Instruments } \\
\text { Instruments are inserted through } \\
\text { the tube }\end{array}$ & $\begin{array}{l}\text { Working Instruments } \\
\text { Instruments are inserted through the working } \\
\text { channel. Instruments are collinear with } \\
\text { endoscope }\end{array}$ & $\begin{array}{l}\text { Working Instruments } \\
\text { Instruments are inserted through the } \\
\text { working portal at an angle from } \\
\text { viewing endoscope }\end{array}$ \\
\hline & $\begin{array}{l}\text { Drill } \\
\text { Air based, standard handle. Bone } \\
\text { dust is washed away by assistant } \\
\text { irrigation and suction. }\end{array}$ & $\begin{array}{l}\text { Drill } \\
\text { Water compatible, long handle, compatible } \\
\text { dimensions according to scope dimensions. } \\
\text { Bone dust is washed away by uniportal } \\
\text { endoscope irrigation }\end{array}$ & $\begin{array}{l}\text { Drill } \\
\text { Water compatible, standard handle. } \\
\text { Bone dust is washed away by viewing } \\
\text { endoscope irrigation and outflow } \\
\text { through working portal. }\end{array}$ \\
\hline & $\begin{array}{l}\text { Energy System } \\
\text { Non water based. Monopolar, } \\
\text { bipolar diathermy }\end{array}$ & $\begin{array}{l}\text { Energy System } \\
\text { Water based low energy, Radiofrequency } \\
\text { ablation in discectomy. Optional usage of } \\
\text { plasma coagulator under spinal compatible } \\
\text { energy setting. }\end{array}$ & $\begin{array}{l}\text { Energy System } \\
\text { Water based low energy, } \\
\text { Radiofrequency ablation of low } \\
\text { energy setting near dura. Definite } \\
\text { usage of plasma coagulator under } \\
\text { spinal compatible energy setting. }\end{array}$ \\
\hline & $\begin{array}{l}\text { Cost of Set Up + (If microscope is } \\
\text { available in operating theatre) }\end{array}$ & $\begin{array}{l}\text { Cost of Set Up +++ (Mainly new equipment } \\
\text { set up, potential use of arthroscopic tower } \\
\text { for endoscope) }\end{array}$ & $\begin{array}{l}\text { Cost of Set Up ++ (Arthroscopic } \\
\text { tower available from Orthopaedics } \\
\text { limb surgery) }\end{array}$ \\
\hline $\begin{array}{l}\text { Placement of } \\
\text { Portal(s) }\end{array}$ & $\begin{array}{l}\text { Fixed tube to table, mobility of } \\
\text { tube limited with aid of table and } \\
\text { microscope tilting and fluoros- } \\
\text { copic guidance when changes are } \\
\text { made in position of tube }\end{array}$ & $\begin{array}{l}\text { Mobile after initial localization by fluoroscopy. } \\
\text { One port } \\
\text { Retractor tube is collinear with endoscope }\end{array}$ & $\begin{array}{l}\text { Mobile after initial localization by } \\
\text { fluoroscopy. } 2 \text { ports independent. } \\
\text { More than } 2 \text { portals are possible. }\end{array}$ \\
\hline $\begin{array}{l}\text { Outflow of } \\
\text { Fluids }\end{array}$ & NA & Inflow and outflow from single port & $\begin{array}{l}\text { Inflow from viewing endoscope port, } \\
\text { outflow from working port }\end{array}$ \\
\hline \multirow[t]{2}{*}{$\begin{array}{l}\text { Route of } \\
\text { Approach }\end{array}$} & $\begin{array}{l}\text { One Port. After skin incision, } \\
\text { layer by layer dissection to } \\
\text { interlaminar space }\end{array}$ & $\begin{array}{l}\text { One port. After skin and fascia incision, } \\
\text { directly docked on area of concern and work } \\
\text { around the docked region in most cases of } \\
\text { transforaminal and interlaminar discectomy } \\
\text { approaches. } \\
\text { Floating technique in stenosis decompression }\end{array}$ & $\begin{array}{l}\text { Two ports. After skin and fascia } \\
\text { incision, working space created } \\
\text { between visualization portal and } \\
\text { working portal } \\
\text { Floating technique. }\end{array}$ \\
\hline & $\begin{array}{l}\text { Level of difficulty in targeting to } \\
\text { specific target pathology: }+++\end{array}$ & $\begin{array}{l}\text { Level of difficulty in targeting to specific } \\
\text { target pathology: + }\end{array}$ & $\begin{array}{l}\text { Level of difficulty in targeting to } \\
\text { specific target pathology: +++ }\end{array}$ \\
\hline
\end{tabular}




\begin{tabular}{|c|c|c|c|}
\hline & $\begin{array}{l}\text { Level of difficulty in approach to } \\
\text { contralateral foramen: Difficult } \\
\text { due to limitation is tubular size } \\
\text { and length, unable to place tube } \\
\text { dorsal to neural elements to } \\
\text { reach contralateral foramen }\end{array}$ & $\begin{array}{l}\text { Level of difficulty in approach to contrala- } \\
\text { teral foramen: easy if switch to smaller } \\
\text { uniportal endoscope. }\end{array}$ & $\begin{array}{l}\text { Level of difficulty in approach to } \\
\text { contralateral foramen: moderate as } \\
\text { space is limited in foramen for both } \\
\text { viewing endoscope and working } \\
\text { instruments. }\end{array}$ \\
\hline \multirow[t]{9}{*}{$\begin{array}{l}\text { Technical } \\
\text { Challenges }\end{array}$} & $\begin{array}{l}\text { Surgical assistant allowed to } \\
\text { retract tissues }\end{array}$ & No assistant & $\begin{array}{l}\text { Surgical assistant allowed to retract } \\
\text { tissues }\end{array}$ \\
\hline & $\begin{array}{l}\text { Limited mobility of vision by angle } \\
\text { of microscope versus bed for } \\
\text { visualization }\end{array}$ & No limits & No limits \\
\hline & $\begin{array}{l}\text { + Limitation of motion in working } \\
\text { instruments. Independent viewing } \\
\text { portal and working portal. } \\
\text { Limited working space in triangu- } \\
\text { lation of microscope and instru- } \\
\text { ments. Angled instruments requi- } \\
\text { red. Not all bone resection can } \\
\text { be directly visualized. Non visuali- } \\
\text { zed bone resection can lead to } \\
\text { inadvertent neural injuries. }\end{array}$ & $\begin{array}{l}\text { +++ Limitation of motion in working instru- } \\
\text { ments as all instruments need to pass } \\
\text { through working channel collinear to the } \\
\text { endoscope. Visualization of tip of instrument } \\
\text { by rotating endoscope which can be } \\
\text { disorientating for beginners. Non visualized } \\
\text { bone resection can lead to inadvertent neural } \\
\text { injuries. }\end{array}$ & $\begin{array}{l}\text { No limitation of motion in working } \\
\text { instruments. Independent viewing } \\
\text { endoscope and working instrument(s). } \\
\text { Triangulation of scope and working } \\
\text { instruments in unlimited working } \\
\text { space, can lead to past pointing and } \\
\text { unintentional injuries to neural } \\
\text { elements. }\end{array}$ \\
\hline & Creation of working space +++ & Creation of working space + & Creation of working space ++ \\
\hline & \begin{tabular}{|l|} 
Soft tissue if not well retracted by \\
working tube, needs to be disse- \\
cted, leading to more collateral \\
soft tissue damages
\end{tabular} & $\begin{array}{l}\text { Soft tissue is manipulated by retractor tube, } \\
\text { less soft tissue bleeding. } \\
\text { Sensitive to bleeding leading to red screen } \\
\text { (poor visualization) }\end{array}$ & $\begin{array}{l}\text { Soft tissue elevated by creating } \\
\text { working space underneath the muscle } \\
\text { Very sensitive to bleeding leading to } \\
\text { red screen }\end{array}$ \\
\hline & Wide $(+++)$ area of vision & Narrow $(+)$ area of vision & Wide $(++)$ area of vision \\
\hline & $\begin{array}{l}\text { Limitation of angle of instrument } \\
\text { by dimension of tube and viewing } \\
\text { microscope }\end{array}$ & $\begin{array}{l}\text { Instrument limited by passing through wor- } \\
\text { king channel. Visualization of the tip of } \\
\text { instruments by rotating endoscope }\end{array}$ & No limitation of angle of instruments \\
\hline & Ease in Hemostasis ++ & Ease in Hemostasis + & Ease in Hemostasis + \\
\hline & Residency training +++ & Residency training +/- & $\begin{array}{l}\text { Residency training }+ \text { (handling of } \\
\text { equipment in orthpaedics limb arthros- } \\
\text { copic procedures) }\end{array}$ \\
\hline \multirow{3}{*}{$\begin{array}{l}\text { Anatomical } \\
\text { Challenges }\end{array}$} & Familiarity +++ & Familiarity + & Familiarity ++ \\
\hline & Residency training +++ & Residency training + & Residency training + \\
\hline & \begin{tabular}{|l|} 
Zero degree visualization, \\
magnification can be adjusted by \\
microscope setting
\end{tabular} & $\begin{array}{l}\text { 10-30 degree visualization can lead to diso- } \\
\text { rientation, magnification can be adjusted by } \\
\text { deeper or shallower insertion of endoscope }\end{array}$ & $\begin{array}{l}0 \text { degree visualization (optional of } \\
30 \text { degree visualization), magnifica- } \\
\text { tion can be adjusted by deeper or } \\
\text { shallow insertion of endoscope } \\
\end{array}$ \\
\hline $\begin{array}{l}\text { Location of Lens } \\
\text { and Light } \\
\text { Source }\end{array}$ & $\begin{array}{l}\text { Outside patients' body in } \\
\text { microscope }\end{array}$ & Inside patient's body at the tip of endoscope & $\begin{array}{l}\text { Inside patient's body at the tip of } \\
\text { endoscope }\end{array}$ \\
\hline $\begin{array}{l}\text { Start Point to } \\
\text { Work }\end{array}$ & Skin & $\begin{array}{l}\text { Sublaminar region, directly on flavum for } \\
\text { interlaminar discectomy under muscle } \\
\text { Kambin's triangle for transforaminal disce- } \\
\text { ctomy under muscle and beyond facet joint } \\
\text { Laminofacet or spinolaminar junction for } \\
\text { stenosis decompression, just above lamina } \\
\text { under muscle } \\
\text { Pars Interarticularis for Paraspinal approach }\end{array}$ & $\begin{array}{l}\text { Spinolaminar junction, just above } \\
\text { lamina under muscle } \\
\text { Pars Interarticularis for Paraspinal } \\
\text { approach }\end{array}$ \\
\hline
\end{tabular}


rent dimensions and requirement for the different approaches. In transforaminal endoscopic lumbar discectomy, the limitation of space in Kambin's safety triangle and the relatively long distance from the skin surface means there is a need for a long and slim endoscope with a correspondingly small working channel as compared to interlaminar approaches. These different dimensions translate into purposed built endoscopic equipment sizes and types of endoscopic equipment. As these equipment are specifically designed for spinal endoscopy, they can be expensive to obtain and make available to the surgeon's local community. Biportal ESS uses ordinary or lightly modified general spinal equipment, arthroscope can be available from general orthopaedic practice with slight modification to fit Biportal ESS practice. There is high reliance of suitable and safe energy source for spine to provide hemostasis in the form of suitable energy radiofrequency ablation. These energy equipment may not be available locally in surgeon's community. As these energy instruments are single use, this can add to the total cost of the procedure.

Before a surgeon embarked a journey for fellowship in endoscopic spine surgery, he should check with the local vendors and community for availability of these specialized endoscopic equipment to make decision on where he should focus on training. As it is costly to set up the equipment required for endoscopy, sufficient volume of cases is needed to make a business case for funding when presenting to hospital management ${ }^{39)}$.

\section{1) Placement of Portal(s), Outflow of Fluids, Route of App- roach, Location of Lens/light Source and Start Point to Work}

In microscopic tubular spine surgery, the retractor tube is fixed to the table after confirmation of position under fluoroscopic guidance. Changes in position is possible with tilting of surgical table and microscope typically with fluoroscopic guidance. The retractor tube is collinear with microscope. A typical docking spot is spinolaminar junction or laminofacet junction. The spinous process anatomy can affect docking position (Figure 3). Soft tissue is dissected after docking to expose the underlying lamina. Surgeons do not encourage frequent changing of position of the working tube as it consumes time in adjustment of surgical table, microscope and fluoroscopy; each change in docking position will require some soft tissue dissection with diathermy ${ }^{111}$.

Figure 3A: Spinous process is deviated to the left side. For tubular retractor placement, spinous process deviation will displace the tube (blue rectangle) towards the left side( blue arrow) as compared to the right side (red rectangle). Figure 3B: 2 typical fluoroscopic guided docking sites for uniportal endoscope and microscopic tubular retractor. Spinolaminar junction( black circle) and laminofacet junction also known as "v"point (red circle). Biportal endoscopic spine surgery converges the viewing endoscope and working instruments to spinolaminar junction (black circle) in the initial period of positioning under fluoroscopic guidance.

Uniportal ESS docked at key bony landmarks or defined safe working space. Once docking is confirmed with aid fluoroscopy, the mobility of endoscope is excellent around the docked region. In TELD, there are numerous approaches described in the literature docking on various landmarks. The 2 commonly described
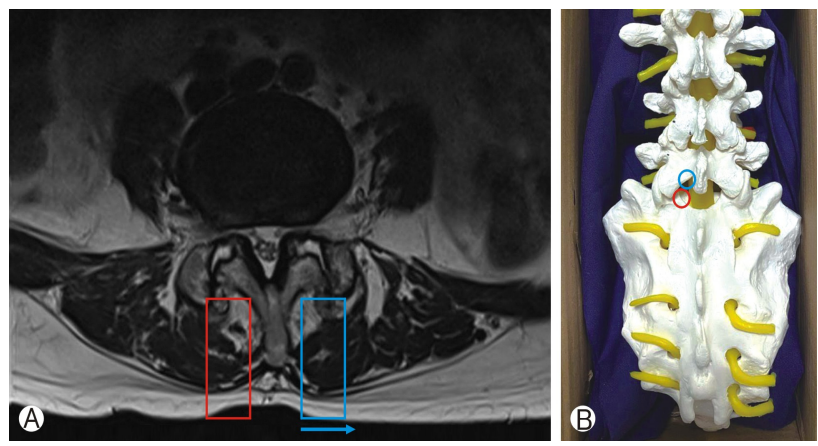

Figure 3. (A): Spinous process is deviated to the left side. For tubular retractor placement, spinous process deviation will displace the tube (blue rectangle) towards the left side (blue arrow) as compared to the right side(red rectangle). (B): 2 typical fluoroscopic guided docking sites for uniportal endoscope and microscopic tubular retractor. Spinolaminar junction (black circle) and laminofacet junction also known as "v"point (red circle). Biportal endoscopic spine surgery convertges the viewing endoscope and working instruments to spinolaminar junction (black circle) in the initial period of positioning under fluoroscopic guidance.
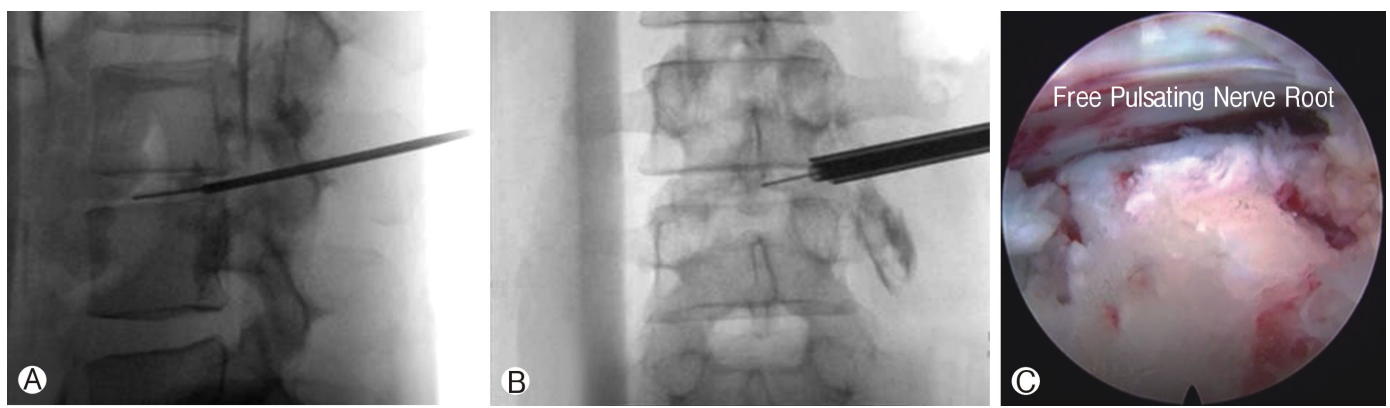

Figure 4. (A): Docking of dilator and guidewire on the distal dorsal aspect of intended intervertebral disc. (B): Mobile outside in technique with dilator and working channel placed at the entrance of foramen at the midline of pedicle on the disc space. (C): Higher degree endoscope of 30 degrees in this case to visualize the free pulsating traversing nerve root. 
docking landmarks are Kambin's triangle in the (inside-out technique) and ventral lateral margin of facet joint in foraminoplasty (outside-in or mobile outside-in technique). Due to the constrain of working space, a higher angle of endoscope (25-35 degrees) are needed to visualize the working space (Figure $4 A-C)^{28)}$.

Figure 4A: Docking of dilator and guidewire on the distal dorsal aspect of intended intervertebral disc. Figure 4B: Mobile outside in technique with dilator and working channel placed at the entrance of foramen at the midline of pedicle on the disc space. Figure 4C: Higher degree endoscope of 30 degrees in this case to visualize the free pulsating traversing nerve root.

In IELD on the other hand, docking is often directly on the superficial portion of ligamentum flavum (Figure 5A and B). in line with the prolapse disc on lateral view and on the shoulder or axilla region of the neural elements on anteroposterior view ${ }^{47)}$. (Figure 5C).

Figure 5A: Interlaminar Endoscopic Lumbar Discectomy, endoscope placed medial to the facet joint of left L5/S1. Figure 5B: Route of advancement for a caudally migrated disc through the axilla region of neural elements, annular defect at the distal portion of the disc paracentral region. Figure 5C: Axillary route $(A x)$ approach to disc between traversing nerve root (TNR) and exiting nerve root (ENR). The shoulder approach places endoscope on the lateral margin of the shoulder of the exiting nerve root.

In LEULBD, the docking point of spinolaminar junction and laminofacet junction ( $\mathrm{V}$-point) are the commonly described anatomical landmarks. The endoscope used in interlaminar approaches is comparatively lower angle of $10-20$ degrees $^{23}$. In higher lumbar levels, the interlaminar space is narrow and it may not be compatible to relatively large uniportal endoscope and retractor dimensions make it difficult to land on the medial aspect of the laminofacet junction ( $\mathrm{V}$-point). A smaller endoscope can be considered after initial bone work with stenosis scope to provide better visualization of higher lumbar level interlaminar space. Preoperative planning on where to dock is imperative for TELD, IELD and LEULBD as the endoscope. After skin and fascia incision, the working retractor is directly docked on area of concern and endoscopic surgery is performed around the docked region. ESS is highly magnified and focus on the region of the pathological anataomy, despite high mobility of uniportal endoscope, erroneous docking would result in significant disorientation and unnecessary collateral soft tissue damages both leading to increase in operative time and risk of complications and/or incomplete decompression. Verification with fluoroscopy can help in orientation, use of navigation can help to do real time orientation while doing endoscopic procedure ${ }^{12)}$. Biportal ESS has a few considerations in terms of position for docking. (1) Viewing portal (VP) is $2-3 \mathrm{~cm}$ away from working portal (WP) to allow space for both endoscope and working instruments to meet in the targeted anatomical region. (2) VP and WP should not be too cephalad in position which would lead to excessive and unnecessary amount of bony decompression. (3) VP and WP should not be too caudal in position which would be inefficient for working instruments to reach the cephalad ligamentum flavum attachment. (4) VP and WP should not be too lateral which would lead to excessive and unnecessary amount of ipsilateral facet dissection and difficulty in reaching contralateral side. (5) In patients with high body mass index, a more lateral entry point is required to visualize contralateral side. (6) For a right handed surgeon, the right side has a more caudal docking point than the left side to limit the amount of cephalad laminotomy for working instruments to gain access to the contralateral side. Position of BESS and UBE are well described in several literature ${ }^{7,16,38)}$. Most articles describe docking point for decompression to be on spinolaminar junction. The position is not fixed and the surgeon can vary the position with considerations made as described above. If surgeon has any doubt about his endoscopic position during surgery, he should perform intraoperative fluoroscopy to clarify the position of his endoscope.

The water inflow and outflow is provided from one port and one scope in uniportal ESS. Obstruction in outflow cannula can lead to blurring of the endoscopic vision. Safety in water pressure and constant inflow and outflow of fluid is paramount to clarity of surgical field and safety to central nervous system. A sustained high pressure of water flow can lead to undesirable complications
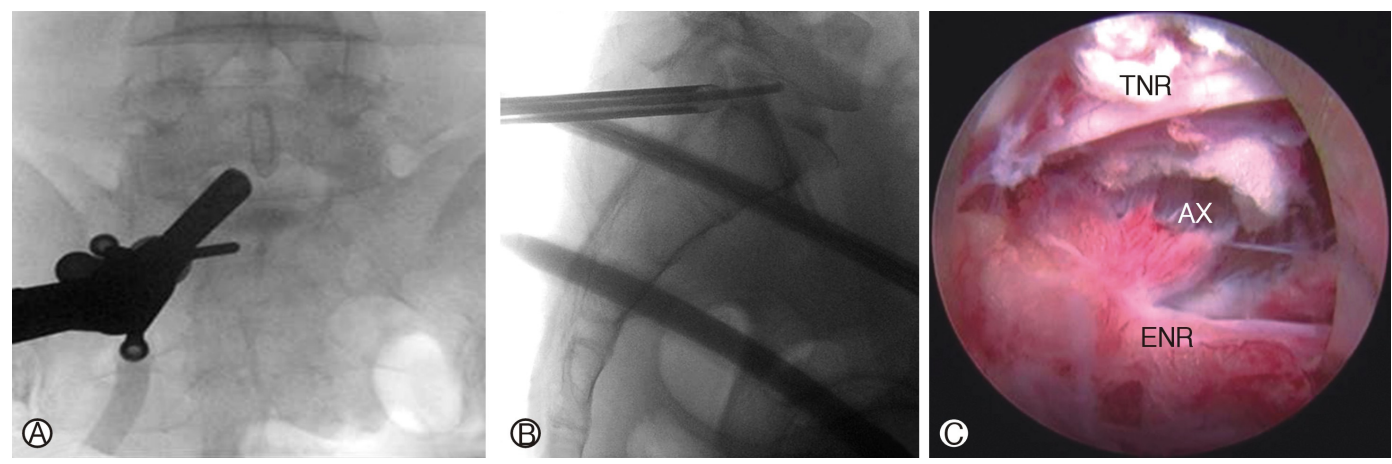

Figure 5. (A): Interlaminar Endoscopic Lumbar Discectomy, endoscope placed medial to the facet joint of left L5/ S1. (B): Route of advancement for a caudally migrated disc through the axilla region of neural elements, annular defect at the distal portion of the disc paracentral region. (C): Axillary route (Ax) approach to disc between traversing nerve root (TNR) and exiting nerve root (ENR). The shoulder approach places endoscope on the lateral margin of the shoulder of the exiting nerve root. 
such as neck pain, cerebral edema, soft tissue edema, hydrothorax, hydroperitoneum ${ }^{22)}$. These complications are rare and is seen mainly in case reports due to a combination of disorientation, violation of soft tissue and high water pressure. While a low water pressure will compromise clarity of vision. Outflow management is important, without proper outflow of fluid, the debris and blood does not wash out and impedes endoscopic vision. An erroneous increase in inflow pressure in an attempt to improve visualization in a blocked outflow will lead to high pressure in spinal region beyond the safety acceptable for ESS. Recent article showed a pressure of $30 \mathrm{mmHg}$ is acceptable and safe for biportal endoscopic spine surgery ${ }^{19)}$. The authors used similar pressure setting for uniportal endoscopic surgery.

\section{2) The location of Lens and Light Source and the Start Point to Work is a Key Conceptual Difference between the 3 Types of Minimally Invasive Surgery}

In microscopic tubular surgery, lens and light source is located in the microscope which is outside the patient's body at the eye level of the surgeon and assistant. Any tissue from the start point of work from skin to the area of interest is retracted/ dissected away to decompress the neural elements and allow visualization at the level of microscope. Some level of soft tissue collateral damage is necessary to allow visualization of tissue from skin to lamina region of the target level. In uniportal and biportal endoscope, the start point is directly on the docked region under the muscle and at times even beyond lamina or facet in discectomy cases. The lens and light source is at the tip of endoscope deep in the patient's body right at the target. This decrease collateral damage in exposure of the tissue for visualization. In biportal ESS, some soft tissue dissection is required for triangulation of VP and WP, which can be assisted by the combination of electric energy system of plasma coagulator, radiofrequency ablator and shaver.

\section{Technical and Anatomical Challenges}

Most of the residents and fellows are used to visualize anatomical structures under microscope in their training .Visualization is more 3D in microscope while 2D in endoscope. They are often given hands on opportunities during their training. Such hands on opportunities are less common in ESS practice. As endoscopic spine surgery (ESS) is a new trend of spine surgery practice, there is a low proportion of endoscopic spine surgeon in most orthopaedic and neurosurgical residency and fellowship training centres. There is generally a lack exposure of ESS techniques during training period of the junior surgeons. There are various ways to learn ESS, such as partaking an endoscopic spine fellowship or observership, participation in cadaveric and dummy workshop. The key limitation in cadaveric workshop is the lack of bleeding and hemostasis required during cadaveric practice. Korean Minimally Invasive Spine Society had recently recognized and accredited some of the international fellowship training centres for endoscopic spine surgery, this is helpful in aspiring ESS fel- lows to make an informed decision on which training centre is suitable to his ESS interest. Several hospitals in different countries also advertised for international endoscopic fellowship ${ }^{52)}$.

There are a few inherent technical challenges in visualization and instruments usage in endoscopic surgery. In microscopic surgery, there is collinear zero degree visualization, magnification can be adjusted by microscope setting. Triangulation of instruments is easy as the instruments are seen directly from skin level to target anatomy by microscope. Angulated instruments help to prevent obstruction of microscopic vision. Working space is created by the working tube and soft tissue dissection, we can engage an assistant surgeon for retraction, suction and suction. An experienced surgeon can be the assistant and partake in majority of the procedures. Multiple instruments can be used simultaneously during procedure ${ }^{11)}$. In Biportal ESS, 0 degree visualization is possible with zero degree scope which can be less disorientating to surgeons. In uniportal ESS, an angled visualization (10-30 degrees) is necessary to visualize the tip of instruments which is working in front of the endoscope. Magnification in both uniportal and biportal ESS is adjusted by pushing the endoscope deeper for more magnification and shallower for lower magnification. However, a helicopter point of view is not possible from uniportal ESS while biportal gave a broader helicopter point of view when instruments are introduced from working portal as viewing portal is independent from working portal. This freedom of viewing and instruments usage comes with a price of possible neural injuries or soft tissue damages by working instruments while scope is setting up a "meeting position "with the instrument. Working port retractor helps to guide instrument safely to the target to prevent inadvertent injuries to neural elements and also create a channel for outflow of water ${ }^{7)}$.

Creation of working space in Biportal ESS is necessary for scope and instruments to safely navigate and work in contralateral sublaminar region this typically required a working distance of $13 \mathrm{~mm}$ between bases of spinous process of cephalad and caudal lamina to accommodate a $8 \mathrm{~mm}$ endoscope and $5 \mathrm{~mm}$ instruments $A$ working space is required for uniportal ESS for $10-13 \mathrm{~mm}$ according to size of stenosis scope to allow the scope to pass through the base of spinous process to contralateral side. Inadequate working space can lead to scope and instruments impingement and possible inadequate decompression. With sufficient working space, there is great mobility of endoscope. The key difference in working instruments mobility is significant among the 3 types of minimally invasive surgery. There is slight limitation of instruments number, mobility and direction by the tube in tubular surgery, very limited instruments mobility in uniportal ESS as all instruments are inserted through working channel and no limitation in numbers of instruments, ports or direction in biportal surgery as viewing and working portals are independent. This limitation is extended to the number of assistant surgeons as well. In microscopic surgery, one assistant is needed due to limited working space in tube and limited viewing lens in microscope limits to one assistant most of the time. In uniportal ESS, there is neither space nor opportunity for an assistant to aid in the surgery, neural and soft tissue retraction is generally done by beveled working retractor rotating 
Pang Hung Wu, et al.

with the opening away from neural structures. In Biportal ESS, one can work with or without assistant according to the surgeon's choice. Some prefer to use working retractor through working channel and scope retractor to retract neural tissue without assistant, while others engage an assistant to hold retractor through the working portal. All observers, assistant and nursing staff can visualize the steps of surgery through the TV output monitor in endoscopic surgery. Despite the differences in technique, the clinical results are comparable in the 3 techniques with better outcomes in early postoperative period in endoscopic surgery ${ }^{15,33)}$.

\section{1) Selection of Cases and Ladder of Progression of Endoscopic Surgery}

There is a steep learning curve in endoscopic spine surgery. ESS surgeons need to be prudent in selection of cases in the early stages of development of ESS practice. We proposed a stepwise progression ladder in the development and selection of cases of ESS for consideration to maximize positive outcomes and minimize complications (Figure 6). There are key challenges and rationale in the construction of this ladder.

\section{2) Interaction with Neural Elements and Handling of Endos- copic Equipment Considerations for Primary Ladder of Competence Progression Model}

TELD as a procedure has several technical nuances to be recommended as the first ESS surgery for uniportal ESS surgeon. The presence of ventral portion of facet and foraminal ligament served as a good protection shield to prevent inadvertent neural injuries. The caveat is that reaming or drilling should not go beyond the medial portion of pedicle on AP fluoroscopic view. Inside out technique is safer than outside in technique for traversing nerve root but tends to have higher rate of dysesthesia in patients with narrow foramen ${ }^{28)}$. IELD can be generally divided into 3 routes to approach the disc. First is the approach to ligamentum flavum which can be split, cut or resected, second is the approach to neural elements which can be shoulder approach or axilla approach, third is the handling of the disc with sequestrectomy, discectomy with or without annuloplasty ${ }^{25,34,35)}$. There is more interaction with neural elements and more delicate handling of working retractor required in IELD as compared to TELD, however there is familiarity of the approach as most surgeons are well trained in posterior approach to the spine during residency.

For most right sided surgeon, left sided L4/5 Biportal ESS surgery is a good start for the first few cases of endoscopic decompression. Left sided approach would allow the instruments to approach the cephalad lamina in a more natural trajectory under vision of left viewing port. Multifidus muscle can be more easily retracted in left sided UBE/BESS, minimizing soft tissue dissection and bleeding. The view for beginner ESS surgeon is more familiar in left side approach when viewing port is held on the left hand in left sided approach ${ }^{6)}$.

\section{3) Soft Tissue and Bony Decompression and Presence of Vascular Structures Considerations for Secondary Ladder of Competence Progression Model}

For LEULBD, there is a need for more bony resection by either endoscopic drill in outside in technique popularized by Kim and

Endoscopic Ladder of Competence Progression Model

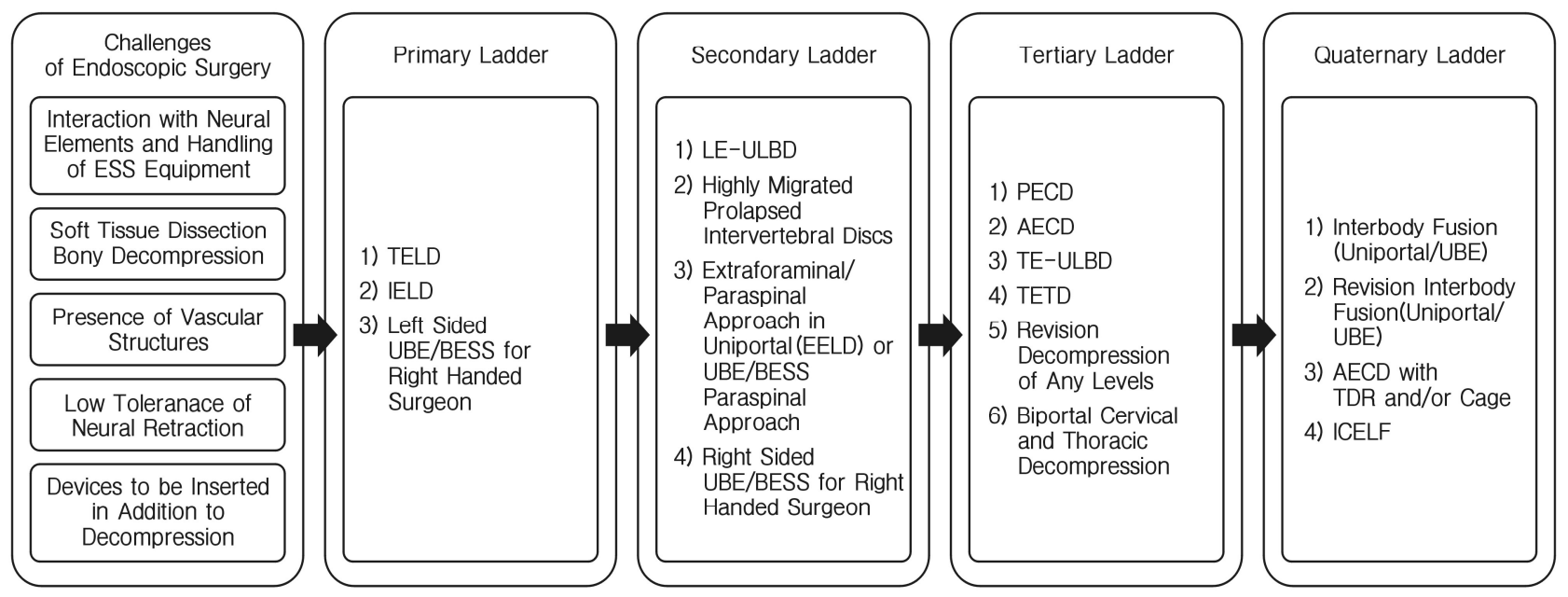

Figure 6. Endoscopic ladder of competence progression model. transforaminal endoscopic lumbar discectomy (TELD), Interlaminar endoscopic lumbar discectomy (IELD), Unilateral biportal endoscopy (UBE), Biportal endoscopic spine surgery (BESS), Lumbar endoscopic unilateral laminotomy bilateral decompression (LE-ULBD), Extraforaminal endoscopic lumbar discectomy (EELD), Posterior endoscopic cervical decompression (PECD), Anterior endoscopic cervical decompression (AECD), Thoracic endoscopic-unilateral kaminotomy bilateral Decompression (TEULBD), Transforaminal endoscopic thoracic discectomy (TETD), Total disc replacement (TDR), Interlaminar contralateral endoscopic lumbar foraminotomy (ICELF). 
Wu et $\mathrm{al}^{23}$, or usage of Kerrison in Inside Out technique popularized by Lim et $\mathrm{al}^{377}$, there is a need to handle more bony elements of the spine, more soft tissue dissection with energy system and the need for endoscope to advance to contralateral side for decompression. All these technical steps present a steep learning curve for ESS surgeon.

Highly migrated disc presents a challenging scenario for both TELD and IELD approaches. There is a risk of inadequate decompression if insufficient bony and soft tissue resection is done to reach the target migrated disc. Often more reaming or endoscopic drilling is required ${ }^{21)}$.

In Extraforaminal or paraspinal approach, the approach is facing directly on the exiting nerve root with its associated radicular artery. The proximity of radicular artery is a challenge to new ESS surgeon, as injury to radicular artery can lead to bleeding which is difficult to control ${ }^{8,10)}$. As this is an unfamiliar surgical anatomy to new ESS surgeon, disorientation with excessive dissection beyond the intertransverse membrane can lead to hemoperitoneum or hydroperitoneum ${ }^{2}$.

Right sided UBE/BESS for right handed surgeon presents with a different angle of vision with the viewing endoscope looking at the lamina from caudal to cephalad and bottom up direction with working instrument coming from the dorsal aspect of lamina. Surgeon tends to make the 2 portals in a slightly more caudal direction to decrease the amount of bone lamina resection required for the working instruments to enter interlaminar space ${ }^{6,8}$.

\section{4) Low Tolerance of Neural Retraction for Tertiary Ladder of Competence Progression Model}

Surgeries at cervical and thoracic region has added risk as these are cord level surgeries. Spinal cord is intolerant of any sort of manipulation and retraction ${ }^{55,57)}$. This is confounded further by the presence of important vascular structures such as vertebral artery in the foramen transversarium and aorta and segmental arteries in thoracic spine. These vascular structures injuries is catastrophic, which can lead to risk of significant morbidity and mortality. In AECD, additional care is given to prevent esophagus and trachea injuries during approach ${ }^{5}$. Hence both anterior and posterior endoscopic cervical and thoracic decompression with uniportal and biportal ESS approaches are advanced level ESS surgeries.

Revision cases tend to have dense adhesion with increased risk of inadvertent dura tear, manipulation of the neural elements is challenging and hence we advised ESS surgeon to be more experienced in ESS and handling of dura tear using endoscopic technique before performing revision endoscopic decompression ${ }^{46)}$.

\section{5) Devices to be Inserted In Addition to Decompression for Quaternary Ladder of Competence Progression Model}

Interbody fusion is challenging in many ways. More bone resection is required with endoscopic drill or osteotome during the procedure. End plate preparation needs to be precise without injuries to end plate which increased risk of subsidence while inadequate preparation increased risk of pseudoarthrosis. Cage insertion under a narrow endoscope channel is often not possible, modified technique is required with modified instruments or specialized cage glider might be necessary. Cage can be placed either under direct endoscopic vision or fluoroscopic guided inser- tion with endoscopic inspection after cage inserted in the interbody space. Fine adjustments can be done after cage is inserted under endoscopic vision ${ }^{31,56)}$. Disc replacement and cage inser- tion in cervical spine and interbody cage insertion in lumbar spine under endoscopic procedures are new surgical techniques in the literature under experts' hands. More data is being evalua- ted for the evolution of these techniques.

Interlaminar contralateral approach has been described in the literature, however the use of a small caliber endoscope through the contralateral foramen from the contralateral side can be disorienting to new ESS surgeon. This anatomical approach is not often explored under training hence the authors felt that it is part of an advanced technique to be done in later stages of ESS surgeons' career ${ }^{26,53)}$.

\section{Potential Complications of Endoscopic Spine Surgery and Management Strategies}

The range of complications for uniportal and biportal endoscopic spinesurgeries are similar as the surgeries are performed in the same anatomical region. While devastating injury such as nerve root injury and paralysis are uncommon in experienced surgeons, common complications such as dura tear, water irrigation related neck or head discomfort, postoperative hematoma and postoperative dysesthesia are common. Fortunately, these complications often can be treated endoscopically and/or with conservative treatment.

\section{1) Dura Tear}

Dura tear rate is approximately $2.7 \%(0-8.6 \%)$ in endoscopic spine surgery ${ }^{27,43,59)}$. The rate is higher in decompression and fusion than discectomy. Early learning curve period tends to have a higher dura tear rate. Dura tear of more than $1 \mathrm{~cm}$ should be considered for conversion to open surgery. For dura tear of $1 \mathrm{~cm}$ and below, several treatment strategies had been proposed. Use of adjuncts such autologous muscle or fat graft in combination with fibrin glue or fibrin sealed collagen sponge is good and safe method for management of dura tear ${ }^{41)}$. Use of tachosil and gel foam construct is popular ${ }^{27)}$. Endoscopic direct repair by stapler anastomoclip and/or sutures are possible ${ }^{14,49)}$.

\section{2) Water Irrigation Related Neck and Head Pain: Postoperative Raise in Intracranial Pressure}

Raised in intracranial pressure secondary to high endoscopic saline inflow can lead to cerebral edema and seizure ${ }^{9,44)}$. Prevention is key to to prevent such complications. Ideal water pressure used is around $30 \mathrm{mmHg}(25-50 \mathrm{mmHg})$, usage of $75-$ $80 \mathrm{mmHg}$ should be limited to less than 30 minutes if needed to prevent neck pain, and postoperative headache. 


\section{6) Hematoma formation}

Postoperative hematoma is a dreadful complication of all spine surgeries, endoscopic spine surgery is of no exception. Kim et al showed a $24.7 \%$ rate of hematoma in biportal endoscopic spine surgery with only $1.2 \%$ developed neurology and required revision surgery because of hematoma ${ }^{32}$. Careful hemostasis is key to prevent postoperative hematoma formation. In the presence of an increase in neurological deficit of bilateral limbs postoperatively, a low threshold for revision decompression and drainage of hematoma is necessary.

\section{4) Postoperative Dysesthesia}

Postoperative dysesthesia is a common complication in surgery involving foraminal diseases, including lumbar foraminal or extraforaminal herniated nucleus pulposus (HNP). Minimal dorsal root ganglion retraction is key to preventing postoperative dysesthesia. Kim et al showed interlaminar contralateral approach has less postoperative dysesthesia rate as compared to transforaminal endoscopic lumbar discectomy ${ }^{24)}$. Preoperative evaluation is key in transforaminal endoscopic lumbar discectomy and foraminotomy surgeries. Narrow foramen or duplicate/conjoined exiting nerve root are signs increased risk of postoperative exiting nerve root dyesthesia. Endoscopic surgeon should either choose an alternative endoscopic strategy or careful superior articular facet decompression before docking the working cannula in an already narrowed foramen".

\section{Summary and Conclusion}

Overall despite the technical, administrative and clinical challenges in endoscopic surgery, its result shows positive impact on patients' outcome. A fellowship or observership with an experienced endoscopic surgeon would be helpful in early stages of endoscopic spine surgery. Consent should be given for possible open conversion from endoscopic spine surgery during early learning period. Understanding the inherent differences in endoscopic techniques to match the requirement of surgeons' patients and institution can help to overcome the steep learning curve of endoscopic spine surgery.

\section{CONFLICT OF INTEREST}

Dr. PH Wu is an editorial board member of the journal but was not involved in the peer reviewer selection, evaluation, or decision process of this article. There are no other potential conflicts of interest relevant to this article to declare.

\section{REFERENCES}

1. Ahn Y: Current techniques of endoscopic decompression in spine surgery. Annals of Translational Medicine 7:S169-S169, 2019

2. Ahn Y, Kim JU, Lee BH, Lee SH, Park JD, Hong DH, et al.: Postoperative retroperitoneal hematoma following transforaminal percutaneous endoscopic lumbar discectomy. J Neurosurg Spine 10:595-602, 2009

3. Akinduro OO, Kerezoudis P, Alvi MA, Yoon JW, Eluchie J, Murad MH, et al.: Open Versus Minimally Invasive Surgery for Extraforaminal Lumbar Disk Herniation: A Systematic Review and Meta-Analysis. World Neurosurg 108:924-938.e923, 2017

4. Arias Garau J: Radiofrequency Denervation of the Cervical and Lumbar Spine. Phys Med Rehabil Clin N Am 29:139-154, 2018

5. Bucknall V, Gibson JA: Cervical endoscopic spinal surgery: A review of the current literature. J Orthop Surg (Hong Kong) 26: 2309499018758520, 2018

6. Choi DJ, Choi CM, Jung JT, Lee SJ, Kim YS: Learning curve associated with complications in biportal endoscopic spinal surgery: Challenges and Strategies. Asian Spine J 10:624-629, 2016

7. Choi DJ, Kim JE: Efficacy of Biportal Endoscopic Spine Surgery for Lumbar Spinal Stenosis. Clin Orthop Surg 11:82-88, 2019

8. Choi DJ, Kim JE, Jung JT, Kim YS, Jang HJ, Yoo B, et al.: Biportal endoscopic spine surgery for various foraminal lesions at the lumbosacral Lesion. Asian Spine J 12:569-573, 2018

9. Choi G, Kang HY, Modi HN, Prada N, Nicolau RJ, Joh JY, et al.: Risk of developing seizure after percutaneous endoscopic lumbar discectomy. J Spinal Disord Tech 24:83-92, 2011

10. Choi G, Lee SH, Bhanot A, Raiturker PP, Chae YS: Percutaneous endoscopic discectomy for extraforaminal lumbar disc herniations: Extraforaminal targeted fragmentectomy technique using working channel endoscope. Spine (Phila Pa 1976) 32:E93-99, 2007

11. Clark AJ, Safaee MM, Khan NR, Brown MT, Foley KT: Tubular microdiscectomy: Techniques, complication avoidance, and review of the literature. Neurosurg Focus 43:E7, 2017

12. Fan G, Han R, Gu X, Zhang H, Guan X, Fan Y, et al.: Navigation improves the learning curve of transforamimal percutaneous endoscopic lumbar discectomy. Int Orthop 41:323-332, 2017

13. Hasan S, Hartl R, Hofstetter CP: The benefit zone of full-endoscopic spine surgery. J Spine Surg 5:S41-S56, 2019

14. Heo DH, Ha JS, Lee DC, Kim HS, Chung HJ: Repair of Incidental Durotomy Using Sutureless Nonpenetrating Clips via Biportal Endoscopic Surgery. Global Spine J 2192568220956606, 2020

15. Heo DH, Lee DC, Park CK: Comparative analysis of three types of minimally invasive decompressive surgery for lumbar central stenosis: Biportal endoscopy, uniportal endoscopy, and microsurgery. Neurosurg Focus 46:E9, 2019

16. Heo DH, Son SK, Eum JH, Park CK: Fully endoscopic lumbar interbody fusion using a percutaneous unilateral biportal endoscopic technique: Technical note and preliminary clinical results. Neurosurg Focus 43:E8, 2017

17. Holly LT, Schwender JD, Rouben DP, Foley KT: Minimally invasive transforaminal lumbar interbody fusion: Indications, technique, and complications. Neurosurgical Focus 20:E6-5, 2006

18. Hwa Eum J, Hwa Heo D, Son SK, Park CK: Percutaneous biportal endoscopic decompression for lumbar spinal stenosis: A technical note and preliminary clinical results. J Neurosurg Spine 24: 602-607, 2016

19. Kang MS, Park HJ, Hwang JH, Kim JE, Choi DJ, Chung HJ: Safety Evaluation of Biportal Endoscopic Lumbar Discectomy: Assessment of Cervical Epidural Pressure During Surgery. Spine (Phila Pa 1976) 45:E1349-e1356, 2020

20. Kapetanakis S, Gkantsinikoudis N, Chaniotakis C, Charitoudis 
Tips and Tricks in Uniportal and Biportal Endoscopic Spine Surgery

G, Givissis P: Percutaneous Transforaminal Endoscopic Discectomy for the Treatment of Lumbar Disc Herniation in Obese Patients: Health-Related Quality of Life Assessment in a 2-Year Follow-Up. World Neurosurg 113:e638-e649, 2018

21. Kim CH, Chung CK, Woo JW: Surgical Outcome of Percutaneous Endoscopic Interlaminar Lumbar Discectomy for Highly Migrated Disk Herniation. Clin Spine Surg 29:E259-266, 2016

22. Kim H-S, Sharma S, Wu P, Raorane H, Adsul N, Singh R, et al.: Complications and limitations of endoscopic spine surgery and percutaneous instrumentation. Indian Spine Journal 3:78-85, 2020

23. Kim H-S, Wu PH, Jang I-T: Lumbar Endoscopic Unilateral Laminotomy for Bilateral Decompression Outside-In Approach: A Proctorship Guideline With 12 Steps of Effectiveness and Safety. Neurospine 17: S99-S109, 2020

24. Kim HS, Kim JY, Wu PH, Jang I-T: Effect of Dorsal Root Ganglion Retraction in Endoscopic Lumbar Decompressive Surgery for Foraminal Pathology: A Retrospective Cohort Study of Interlaminar Contralateral Endoscopic Lumbar Foraminotomy and Discectomy versus Transforaminal Endoscopic Lumbar Foraminotomy and Discectomy. World Neurosurgery 2021

25. Kim HS, Park JY: Comparative assessment of different percutaneous endoscopic interlaminar lumbar discectomy (PEID) techniques. Pain Physician 16:359-367, 2013

26. Kim HS, Patel R, Paudel B, Jang I-T, Jang J-S, Oh S-H, et al.: Early Outcomes of Endoscopic Contralateral Foraminal and Lateral Recess Decompression via an Interlaminar Approach in Patients with Unilateral Radiculopathy from Unilateral Foraminal Stenosis. World Neurosurgery 108:763-773, 2017

27. Kim HS, Raorane HD, Hung WP, Heo DH, Sharma SB, Jang IT: Incidental Durotomy during Endoscopic Stenotic Lumbar Decompression (ESLD): Incidence, classification and proposed management strategies. World Neurosurg 2020

28. Kim HS, Raorane HD, Wu PH, Yi YJ, Jang IT: Evolution of endoscopic transforaminal lumbar approach for degenerative lumbar disease. Journal of Spine Surgery 2020

29. Kim HS, Wu PH, Jang I-T: Current and Future of Endoscopic Spine Surgery: What are the Common Procedures we Have Now and What Lies Ahead? World Neurosurgery 140:642-653, 2020

30. Kim HS, Wu PH, Jang I-T: Development of Endoscopic Spine Surgery for Healthy Life: To Provide Spine Care for Better, for Worse, for Richer, for Poorer, in Sickness and in Health. Neurospine 17:S3-S8, 2020

31. Kim HS, Wu PH, Jang I-T: Technical note on Uniportal full endoscopic posterolateral approach transforaminal lumbar interbody fusion with reduction for grade 2 spondylolisthesis. Interdisciplinary Neurosurgery 21:100712, 2020

32. Kim JE, Choi DJ, Park EJ: Evaluation of Postoperative Spinal Epidural Hematoma After Biportal Endoscopic Spine Surgery for Single-Level Lumbar Spinal Stenosis: Clinical and Magnetic Resonance Imaging Study. World Neurosurg 126:e786-e792, 2019

33. Lee C-W, Yoon K-J, Ha S-S: Comparative Analysis between Three Different Lumbar Decompression Techniques (Microscopic, Tubular, and Endoscopic) in Lumbar Canal and Lateral Recess Stenosis: Preliminary Report. BioMed Research International 2019: 6078469-6078469, 2019

34. Lee J-S, Kim H-S, Jang J-S, Jang I-T: Structural Preservation
Percutaneous Endoscopic Lumbar Interlaminar Discectomy for L5-S1 Herniated Nucleus Pulposus. BioMed Research International 2016:6250247-6250249, 2016

35. Lee U, Kim CH, Kuo CC, Choi Y, Park SB, Yang SH, et al.: Does Preservation of Ligamentum Flavum in Percutaneous Endoscopic Lumbar Interlaminar Discectomy Improve Clinical Outcomes? Neurospine 16:113-119, 2019

36. Lener S, Wipplinger C: Defining the MIS-TLIF: A Systematic Review of Techniques and Technologies Used by Surgeons Worldwide 10:151s-167s, 2020

37. Lim KT, Nam HGW, Kim SB, Kim HS, Park JS, Park CK: Therapeutic Feasibility of Full Endoscopic Decompression in Oneto Three-Level Lumbar Canal Stenosis via a Single Skin Port Using a New Endoscopic System, Percutaneous Stenoscopic Lumbar Decompression. Asian Spine J 13:272-282, 2019

38. Lin GX, Huang P, Kotheeranurak V, Park CW, Heo DH, Park CK, et al.: A Systematic Review of Unilateral Biportal Endoscopic Spinal Surgery: Preliminary Clinical Results and Complications. World Neurosurg 125:425-432, 2019

39. Manabe H, Tezuka F, Yamashita K, Sugiura K, Ishihama Y, Takata Y, et al.: Operating Costs of Full-endoscopic Lumbar Spine Surgery in Japan. Neurol Med Chir (Tokyo) 60:26-29, 2020

40. McHugh SM, Hill AD, Humphreys H: Laminar airflow and the prevention of surgical site infection. More harm than good? Surgeon 13:52-58, 2015

41. Muller SJ, Burkhardt BW, Oertel JM: Management of Dural Tears in Endoscopic Lumbar Spinal Surgery: A Review of the Literature. World Neurosurg 119:494-499, 2018

42. Parikh K, Tomasino A, Knopman J, Boockvar J, Härtl R: Operative results and learning curve: Microscope-assisted tubular microsurgery for 1- and 2-level discectomies and laminectomies. Neurosurg Focus 25:E14, 2008

43. Park H-J, Kim S-K, Lee S-c, Kim W, Han S, Kang S-S: Dural Tears in Percutaneous Biportal Endoscopic Spine Surgery: Anatomical Location and Management. World Neurosurgery 2020

44. Parpaley Y, Urbach H, Kovacs A, Klehr M, Kristof RA: Pseudohypoxic brain swelling (postoperative intracranial hypotensionassociated venous congestion) after spinal surgery: Report of 2 cases. Neurosurgery 68:E277-283, 2011

45. Roche NC, Raynaud L, Bompaire F, Lucas JJ, Auxéméry Y: Perstimulus asystole during electroconvulsive therapy: Clinical case and critical literature review. Encephale 42:59-66, 2016

46. Ruetten S, Komp M, Merk H, Godolias G: Recurrent lumbar disc herniation after conventional discectomy: A prospective, randomized study comparing full-endoscopic interlaminar and transforaminal versus microsurgical revision. J Spinal Disord Tech 22:122-129, 2009

47. Sebastian R, Martin K, Harry M, Georgios G: Use of newly developed instruments and endoscopes: Full-endoscopic resection of lumbar disc herniations via the interlaminar and lateral transforaminal approach. Journal of Neurosurgery: Spine SPI 6:521530, 2007

48. Sen RD, White-Dzuro G, Ruzevick J, Kim CW, Witt JP, Telfeian AE, et al.: Intra- and Perioperative Complications Associated with Endoscopic Spine Surgery: A Multi-Institutional Study. World Neurosurg 120:e1054-e1060, 2018

49. Shin JK, Youn MS, Seong YJ, Goh TS, Lee JS: Iatrogenic dural tear in endoscopic lumbar spinal surgery: Full endoscopic dural 
suture repair (Youn's technique). European Spine Journal 27: 544-548, 2018

50. Soliman HM: Irrigation endoscopic discectomy: A novel percutaneous approach for lumbar disc prolapse. Eur Spine J 22: 10371044, 2013

51. Suarez-Ahedo C, Pavan Vemula S, Stake CE, Finley ZA, Martin TJ, Gui $\mathrm{C}$, et al.: What are the current indications for use of radiofrequency devices in hip arthroscopy? A systematic review. J Hip Preserv Surg 2:323-331, 2015

52. Wu PH: Early Career Challenges in Setting Up an Endoscopic Spine Surgery Practice. World Neurosurgery 144:264-269, 2020

53. Wu PH, Kim HS, Jang I-T: How I do it? Uniportal full endoscopic contralateral approach for lumbar foraminal stenosis with double crush syndrome. Acta Neurochirurgica 2019

54. Wu PH, Kim HS, Jang I-T: A Narrative Review of Development of Full-Endoscopic Lumbar Spine Surgery. Neurospine 17:S20S33, 2020

55. Wu PH, Kim HS, Kim J-Y, Lee YJ, Kim DH, Lee JH, et al.: Uniportal thoracic endoscopic decompression using one block resection technique for thoracic ossified ligamentum flavum technical report. Interdisciplinary Neurosurgery 23:100963, 2021

56. Wu PH, Kim HS, Lee YJ, Kim DH, Lee JH, Jeon JB, et al.: Uniportal Full Endoscopic Posterolateral Transforaminal Lumbar Interbody Fusion with Endoscopic Disc Drilling Preparation Technique for Symptomatic Foraminal Stenosis Secondary to Severe Collapsed Disc Space: A Clinical and Computer Tomog- raphic Study with Technical Note. Brain Sci 10, 2020

57. Wu PH, Kim HS, Lee YJ, Kim DH, Lee JH, Yang K-H, et al.: Posterior endoscopic cervical foramiotomy and discectomy: Clinical and radiological computer tomography evaluation on the bony effect of decompression with 2 years follow-up. European Spine Journal 2020

58. Yeung AT, Tsou PM: Posterolateral endoscopic excision for lumbar disc herniation: Surgical technique, outcome, and complications in 307 consecutive cases. Spine (Phila Pa 1976) 27:722-731, 2002

59. Zhou C, Zhang G, Panchal RR, Ren X, Xiang H, Xuexiao M, et al.: Unique Complications of Percutaneous Endoscopic Lumbar Discectomy and Percutaneous Endoscopic Interlaminar Discectomy. Pain Physician 21:E105-e112, 2018 